\title{
Spatiotemporal Properties of Short-Term Plasticity in Sensorimotor Thalamocortical Pathways of the Rat
}

\author{
Manuel A. Castro-Alamancos and Barry W. Connors \\ Department of Neuroscience, Brown University, Providence, Rhode Island 02912
}

Each region of neocortex receives synaptic input from several thalamic nuclei, but the response properties of thalamocortical pathways may differ. We have studied the frontoparietal (motor and somatosensory) neocortex of the rat and have examined the responses induced by stimulating two convergent thalamocortical projections originating in the ventrolateral $(V L)$ nucleus and ventroposterior lateral (VPL) nucleus. Depth recordings and current-source density (CSD) analysis revealed two primary responses with different laminar and temporal patterns when VL and VPL were stimulated. Single shocks to VL produced a characteristic small current sink in layer $V$, which strongly enhanced in response to a second pulse delivered within a 50 200 msec interval (i.e., the augmenting response). In contrast, a shock to VPL evoked a large current sink that originated in layer IV, spread strongly into the supragranular layers, and was almost abolished in response to a second pulse at intervals of $<200$ msec (i.e., the decremental response). Control experi- ments determined that these responses could not be attributed to the antidromic firing of corticothalamic cells, intrathalamic mechanisms, or anesthesia. Topographic response maps were obtained from a grid of 30 sites across frontoparietal cortex. One shock to VL excited a very limited cortical region, but an augmenting response evoked $50-200 \mathrm{msec}$ later spread at $\sim 1$ $\mathrm{m} / \mathrm{sec}$ to synchronize the activity across an area up to 25 times larger. In contrast, a single shock to VPL activated a relatively large area, but the area activated by a second shock delivered within $200 \mathrm{msec}$ was much smaller. We conclude that overlapping thalamocortical projections, originating in different thalamic nuclei, have distinct spatiotemporal response characteristics that may serve the functional specializations of these pathways.

Key words: thalamus; neocortex; augmenting response; short-term plasticity; thalamocortical; somatosensory cortex; motor cortex
Stimulation of dorsal thalamic nuclei evokes frequencydependent responses in neocortex (Dempsey and Morison, 1942a,b, 1943; Morison and Dempsey, 1942, 1943). The "primary response" has a short latency and biphasic (surface positive negative) shape and is recorded in restricted cortical areas. Repetitive stimulation of the thalamus at $7-14 \mathrm{~Hz}$ can evoke "augmenting responses," which increment during the first several stimuli and are surface-positive and middle-layer negative [augmenting responses of thalamocortical pathways should not be confused with the widespread synaptic phenomenon of "augmentation" (Zucker, 1989)]. Primary and augmenting responses are evoked from the same thalamic locations and should be distinguished from the other major type of thalamocortical response, the recruiting response (Steriade et al., 1990).

Primary responses are assumed to result from the monosynaptic projection of specific thalamic nuclei to middle cortical layers (primarily layer IV). Each specific thalamocortical projection synapses mainly onto neurons of layer IV and the basal dendrites of layer III cells (White, 1986). Augmenting responses were attributed originally to purely thalamic mechanisms (Dempsey and Morison, 1943); however, recent studies have concluded that cortical processes are primarily responsible (Morin and Steriade,

Received Nov. 27, 1995; revised Jan. 24, 1996; accepted Jan. 30, 1996.

This work was supported by fellowships from the Ministry of Science and Education of Spain and the National Institute of Mental Health (MH19118) to M.A.C., and grants from National Institutes of Health (NS25983) and the Office of Naval Research (N00014-90-J-1701) to B.W.C. We thank J. T. Smith for technical assistance.

Correspondence should be addressed to Manuel A. Castro-Alamancos, Box 1953, Department of Neuroscience, Brown University, Providence, RI 02912.

Copyright 1996 Society for Neuroscience $0270-6474 / 96 / 162767-13 \$ 05.00 / 0$
1981; Ferster and Lindstrom, 1985a,b; Metherate and Ashe, 1994).

The ventrolateral (VL) and ventroposterior lateral (VPL) nuclei of the thalamus provide topographically organized projections to the sensorimotor cortex of the rat (Donoghue et al., 1979). Here we report results of a study comparing the cortical responses to stimulation of the VL and VPL nuclei. The principle aim was to describe the laminar, spatial, and temporal properties, as well as the short-term plasticity, of responses in frontoparietal neocortex to stimulation of two thalamic nuclei with convergent projections. The anesthetized rat is quite suitable for thesc studics because both the VL and VPL nuclei, although adjacent, can be stimulated independently. In addition, the cortical projection regions of these nuclei are easily accessible, facilitating mapping of activity across the surface and depth. Because the cortical projections of the two nuclei are known to overlap anatomically (Donoghue et al., 1979), it is also likely that their functions interact. Our results show that the laminar patterns of activation and the spatiotemporal properties of short-term plasticity in these convergent thalamocortical projections are strikingly different.

\section{MATERIALS AND METHODS}

Fifty adult Sprague-Dawley rats (250-350 gm) were anesthetized with ketamine $\mathrm{HCl}(100 \mathrm{mg} / \mathrm{kg}$, i.p.) and supplemented regularly $(50 \mathrm{mg} / \mathrm{kg}$, i.m.). After induction of surgical anesthesia, the animal was placed in a stereotaxic frame. All skin incisions and frame contacts with the skin were injected with lidocaine $(2 \%)$. A unilateral craniotomy extended over a large area of the parietofrontal cortex. Small incisions were made in the dura as necessary, at the locations of insertion of the stimulating and recording electrodes. The cortical surface was covered with saline for the duration of the experiment. Body temperature was monitored and maintained constant with a heating pad $\left(36-37 \mathrm{C}^{\circ}\right)$. All surgical procedures 
were reviewed and approved by the institutional animal care and use committee of Brown University.

Thalamic stimulating electrodes were inserted stereotactically (all coordinates are given in millimeters, referred to bregma and the dura according to the atlas of Paxinos and Watson, 1982). Coordinates for the VL nucleus were approximate as follows: anterior-posterior $=-2.0$, lateral $=2.0$, depth $=5.5$; for the VPL nucleus, anterior-posterior $=$ -2.0 , lateral $=3.0$, depth $=5.5-6.5$. Stimulus current intensity was selected to induce a stable response $(<200 \mu \mathrm{A}$ unless noted otherwise), and stimuli were monophasic and $200 \mu \mathrm{sec}$ in duration. Insulated, twisted, bipolar stainless steel electrodes were used for stimulation.

Recording electrodes were Teflon-insulated platinum-iridium wires ( 0.007 inch diameter, 0.005 inch tip size). In all experiments, two recording electrodes were placed simultaneously in two of 30 possible cortical sites (see Fig. 1A). Typically, recordings were obtained at $0,500,1000$, 1500 , and $2000 \mu \mathrm{m}$ below the surface of the pia mater. When currentsource density (CSD) analysis was performed from a particular site, the average of 20 responses was obtained from each depth at $100 \mu \mathrm{m}$ intervals, from the surface to $2000 \mu \mathrm{m}$ deep. When recordings were destined for CSD analysis, care was taken to make penetrations normal to the pial surface. CSDs were calculated by approximating the second spatial derivative of voltage using the methods described by Mitzdorf (1985). Two methods were used to control for the stability of the preparation during long recording sessions. First, the moving electrodes were always returned to their initial recording sites, and measurements from those sites were repeated to ensure that no significant change over time had occurred. Second, the electrocorticogram was monitored continuously for stability.

At the end of each experiment, electrolytic marking lesions were placed at the thalamic locations that had served as stimulation sites. The animals were given an overdose of sodium pentobarbital and decapitated, and the brain was extracted and placed in fixative solution (5\% paraformaldehyde in saline). Subsequently, slices of the frontoparietal cortex and thalamus were cut with a vibratome and stained for Nissl (see Fig. $1 B-D$ ).

Cortical recording sites were characterized in several ways. Brief, high-frequency trains of stimuli $(300 \mathrm{~Hz}, 40 \mathrm{msec}$ train duration; $<60$ $\mu \mathrm{A})$ were applied through the recording electrode into the infragranular layers; discrete movements indicated that the electrode was situated in primary motor cortex (Castro-Alamancos and Borrell, 1993, 1995). In some cases, extracellular spikes were recorded, and their response to tactile stimulation of various body parts was assessed to identify primary somatosensory cortex. This was done by monitoring the multiunit activity with an audio amplifier and observing the effect of "brushing" the hair and skin with a hand-held probe. Recording sites were also characterized by their distinctive response to stimulation of the thalamus (as described in Results). Finally, recording locations were mapped histologically (see Fig. $1 D$ ), and their coordinates were compared with previously obtained maps of the rat somatosensory and motor cortex (Hall and Lindholm, 1974; Castro-Alamancos and Borrell, 1993, 1995).

When substances were infused into the cortex or thalamus, a pipette $(75 \mu \mathrm{m})$ or a microdialysis probe was placed adjacent to the recording or stimulating electrode, respectively, and lowered simultaneously into the tissue. After obtaining a stable response, the drugs were infused by applying pressure to a Hamilton syringe, which was connected to the pipette placed in the tissue, or by microdialysis, as described previously (Castro-Alamancos and Torres-Aleman, 1993).

Procedures for implanting electrodes in freely moving animals have been described previously (Castro-Alamancos and Borrell, 1995). Electrophysiological recordings were performed as in anesthetized animals, but with field-effect transistors (NBLABS, Dennison, TX) attached to the recording electrodes within the head connectors. During recording sessions, the animals were placed in an open field (17 inches $\times 17$ inches).

Electrophysiological responses were sampled at $10 \mathrm{KHz}$ and stored and analyzed on a computer using Experimenter's Workbench (Data Wave Technologies, Longmont, CO) and Origin (Microcal Software, Northampton, MA) software.

\section{RESULTS}

\section{Characterization of cortical responses and thalamic stimulation sites}

Figure 2 shows representative responses of motor cortex to single stimuli of the VL nucleus (see Fig. $1 B$ for a typical VL
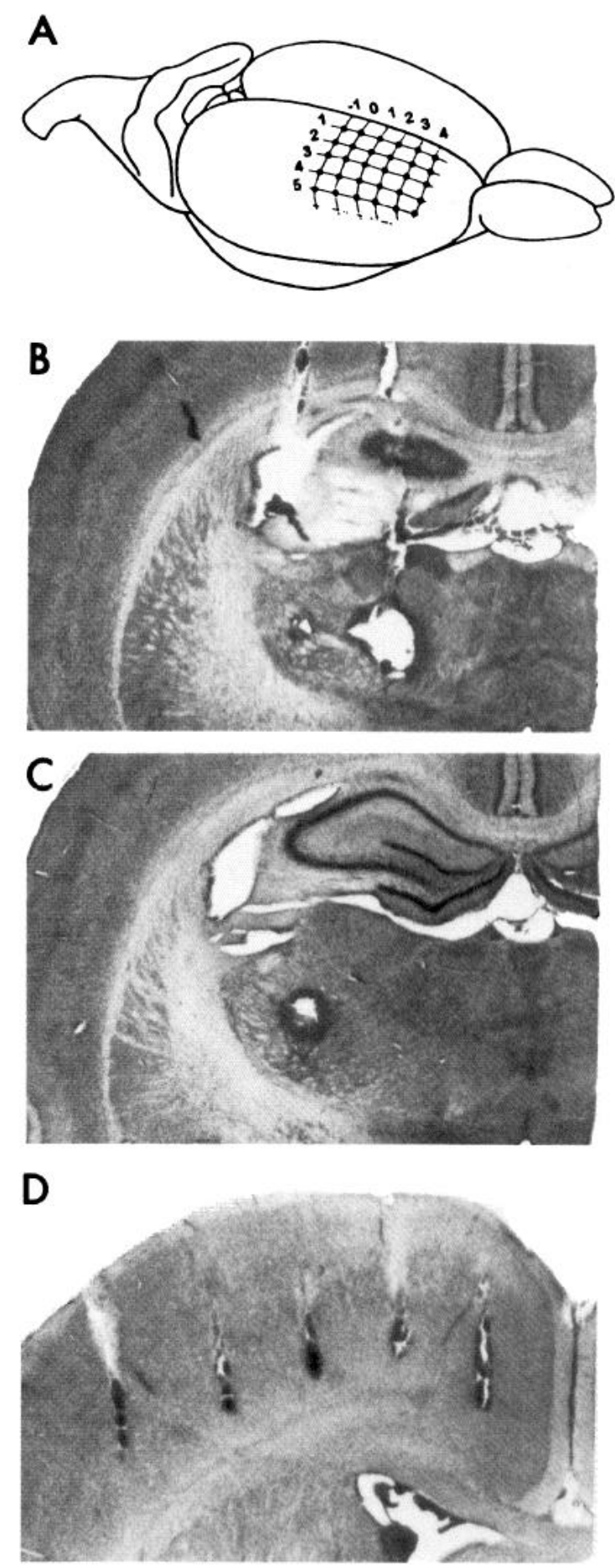

Figure 1. Recording and stimulation sites in cortex and thalamus. $A$, Schematic diagram illustrating the grid placement of recording sites. $B$, Nissl-stained coronal section through the thalamus showing two electrode tracks marking positions of VL (medial track) and VPL (lateral track) stimulation sites. Marking lesions were made after recordings by applying $1 \mathrm{~mA}$ for $10 \mathrm{sec}$ through each electrode. $C$, Coronal section posterior to the one shown in $B$. At this location, only the lesion corresponding to the VPL-stimulating electrode was visible. $D$, Coronal section through the frontoparietal cortex showing the tracks of five recording electrodes used to generate the topographic activity maps, as shown in $A$.

stimulation site). Field potentials recorded through the depth of the cortex (Fig. 2, left), CSD traces calculated from those potentials (Fig. 2, middle), and a color-coded contour plot of the CSD (Fig. 2, right) are illustrated. VL stimuli evoked a 
Field Potential

CSD

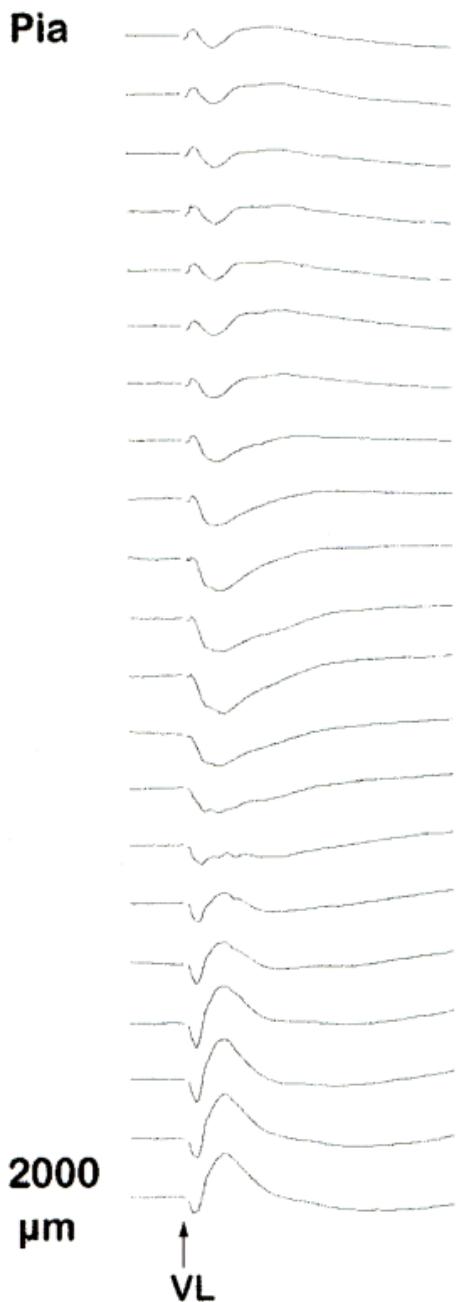

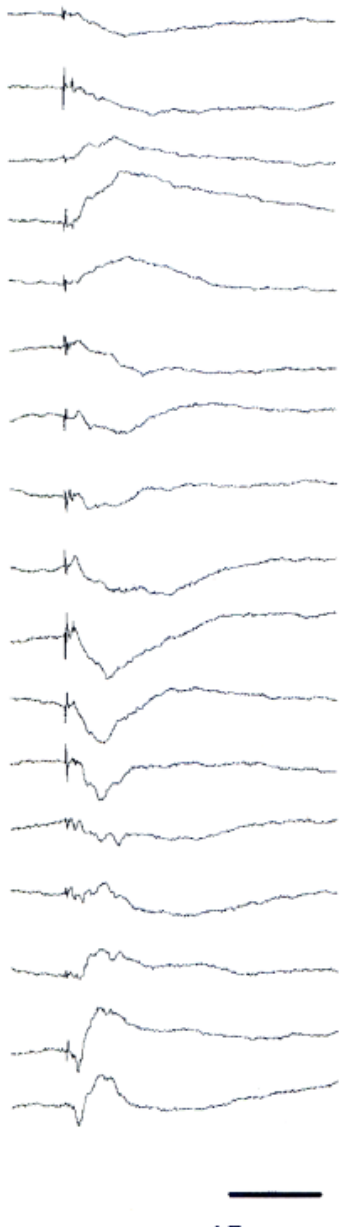

$15 \mathrm{msec}$
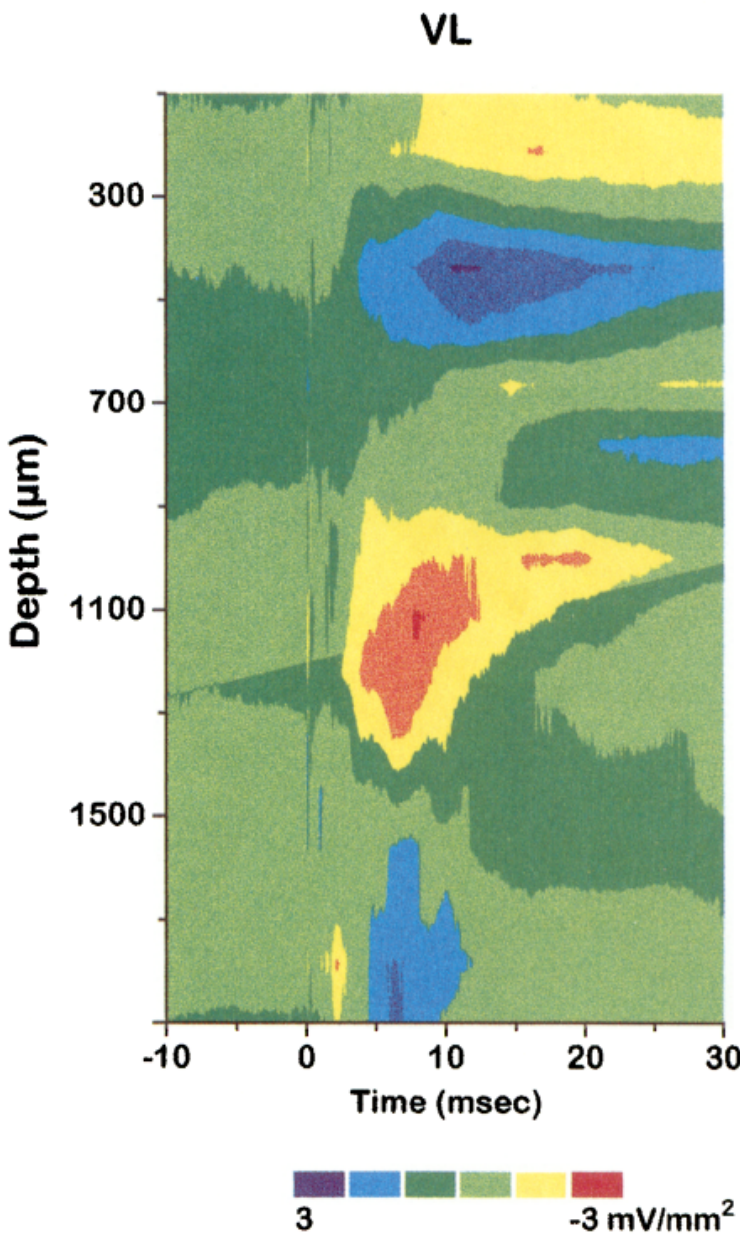

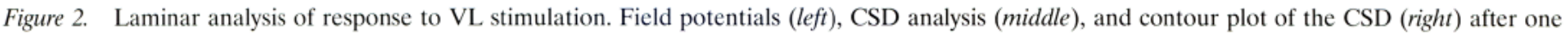

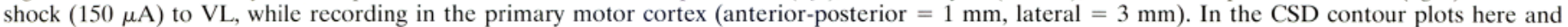

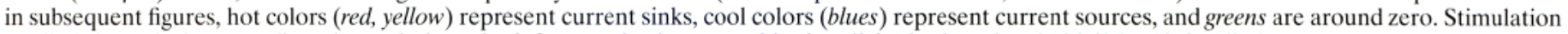
applied through the recording electrode into the infragranular layers at this site elicited a low threshold (25 $\mu \mathrm{A})$ forelimb movement.

characteristically small negative field potential that peaked at $\sim 0.5 \mathrm{mV}$ within layer $\mathrm{V}(800-1300 \mu \mathrm{m}$ from the surface; the depth of shortest latency sink from six rats was $1175 \pm 65 \mu \mathrm{m}$, mean $\pm \mathrm{SD})$. Application of infragranular layer microstimulation $(25 \mu \mathrm{A})$ through the recording electrode evoked lowthreshold forelimb movements. CSD analysis revealed shortlatency (i.e., $3 \mathrm{msec}$ ) current sinks originating within layer $\mathrm{V}$, with coincident current sources in supragranular layers. This is the "primary response" of the motor cortex to VL stimulation.

Figure 3 shows similarly displayed primary responses to stimulation of the VPL nucleus (see Fig. $1 B, C$ for a typical VPL stimulation site) while recording in the somatosensory cortex (no movement was observed when intracortical microstimulation was applied at this site). Relatively large $(>1 \mathrm{mV})$ negative field potentials were evoked, corresponding to a large current sink initiated at short latency ( $3 \mathrm{msec})$ within layer IV $(800-900 \mu \mathrm{m}$ deep; the depth of the shortest latency sink from six rats was 835 $\pm 50 \mu \mathrm{m}$, mean $\pm \mathrm{SD}$ ). During the next $10 \mathrm{msec}$, this sink shifted progressively higher into layer II-III, whereas a current source shifted in the opposing direction (see also Fig. 4B).
Histology of the thalamic stimulation sites confirmed that stimulating electrodes were placed in the appropriate thalamic nucleus (VL or VPL) when responses with these characteristics were observed (see Fig. 1B,C). In addition, responses of these types were not observed in the frontoparietal cortex when stimuli were applied to locations outside the coordinates of the VL and VPL nuclei. Results presented here are representative examples and are based on more than 200 CSDs derived from 50 rats.

\section{Temporal and spatial characteristics of paired VL-to-cortex responses}

When two VL stimuli were delivered at a $100 \mathrm{msec}$ interstimulus interval, the second response was much larger than the first (Fig. $4 A$ ). This augmenting response displayed a current source in the upper layers, paired with a large current sink in the middle layers (900-1200 $\mu \mathrm{m}$ deep). Although the primary responses peaked at $\sim 8 \mathrm{msec}$, the second, augmenting response peaked at $15 \mathrm{msec}$. The augmenting response was evident for only a limited range of 
Field Potential

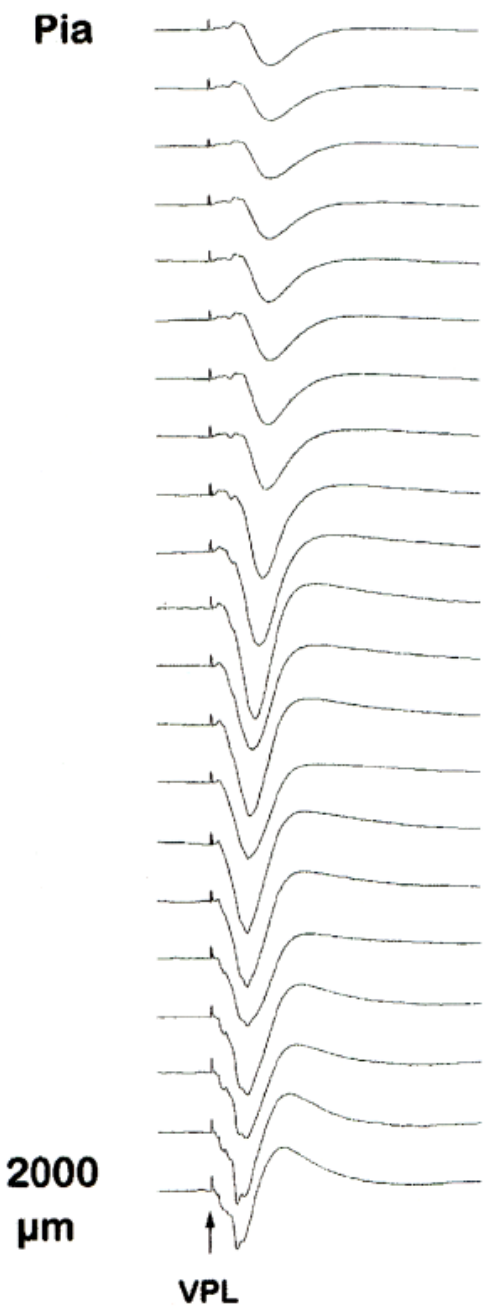

CSD

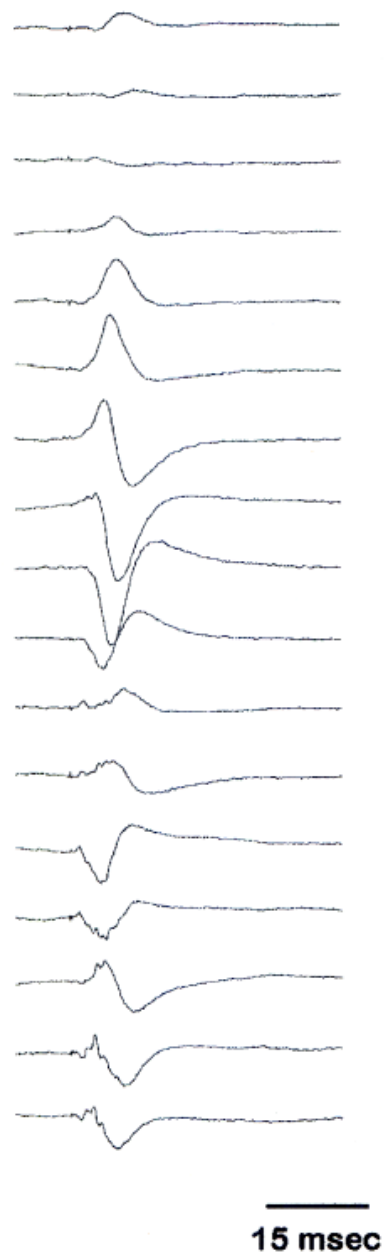

rat22m2y

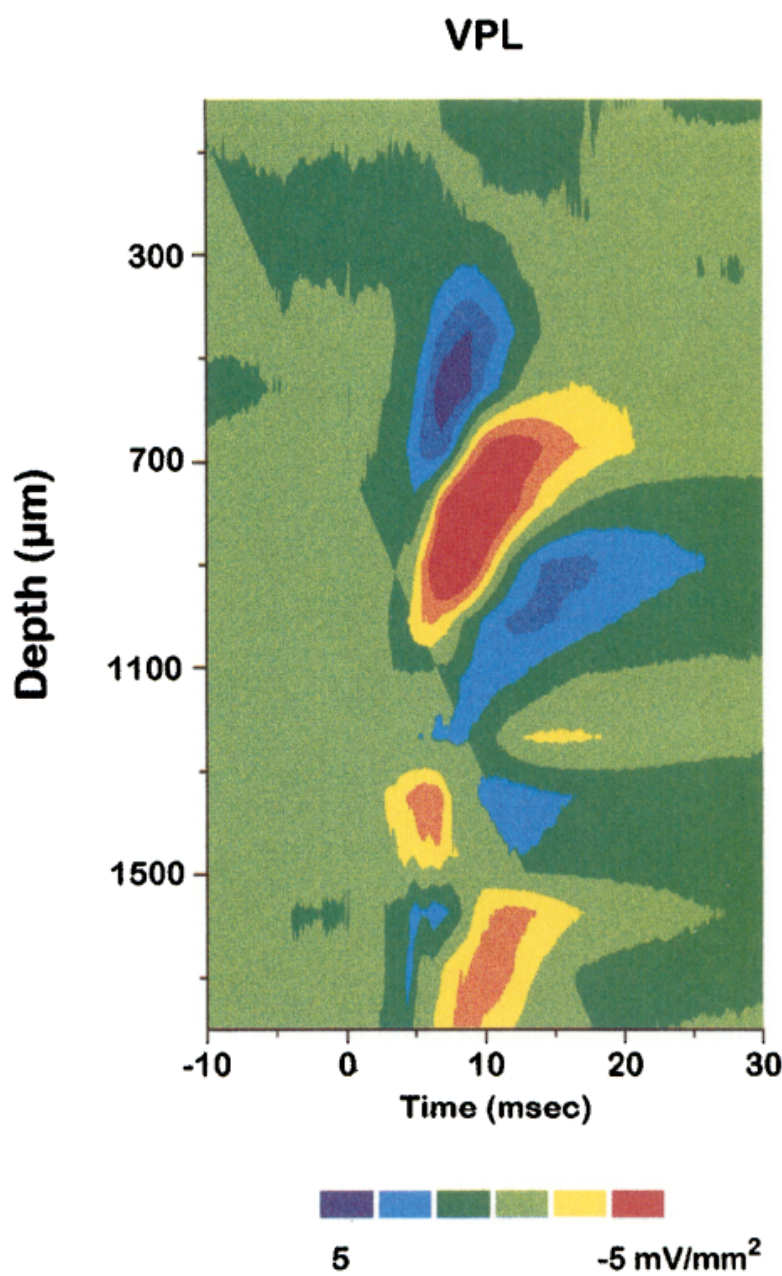

Figure 3. Laminar analysis of response to VPL stimulation. Field potentials (left), CSD analysis (middle), and contour plot of the CSD (right) after one shock $(150 \mu \mathrm{A})$ to VPL, while recording in the somatosensory cortex (anterior-posterior $=1 \mathrm{~mm}$, lateral $=4 \mathrm{~mm}$ ). No movements were elicited from stimulating $(60 \mu \mathrm{A})$ the infragranular layers at this location.

interstimulus intervals between 50 and $200 \mathrm{msec}$ (Fig. 5, filled circles), with a peak effect at $\sim 100$ msec.

The topographic characteristics of responses to paired VL stimuli (100 msec interval) were mapped by recording from multiple locations spaced $1 \mathrm{~mm}$ apart in frontoparietal cortex (see Fig. $1 A, D$; penetrations $5 \mathrm{~mm}$ lateral were excluded in this case). The peak negative field potential, corresponding in latency to the middle layer current sink (see Figs. 2, 4A), was measured and plotted for each recording site. Contour plots from various subpial depths (Fig. 6A) show that the response to the first stimulus is spatially localized and of low amplitude, whereas the second response is much larger in size and covers a much larger volume of cortex, both tangentially and through the depth. Figure $6 B$ shows how the topographic map (here at a depth of $1500 \mu \mathrm{m}$ ) unfolds in time. The primary response to the first stimulus appears at a latency of 3-5 msec and remains spatially restricted; the beginning of the augmenting response to the second stimulus is evident only at $7 \mathrm{msec}$, but quickly spreads to encompass a much larger area. For example, at a depth of $1500 \mu \mathrm{m}$, the cortical area encompassing responses $>0.5 \mathrm{mV}$ was 25 times greater after the second stimulus than after the first in this case. By measuring the delays of the response from one grid site to the next, we estimated that the augmenting response spreads through the cortex at a velocity of $\sim 0.8-1.1 \mathrm{~m} / \mathrm{sec}$. Recordings from multiple sites in response to VL stimulation, as shown in Figure 6, were conducted in six rats with similar results.

These results indicate that the augmenting response originates at the region of the primary response and spreads rapidly to adjacent cortical regions.

\section{Temporal and spatial characteristics of paired VPL-to-cortex responses}

In contrast to VL-to-cortex responses, paired stimuli delivered to the VPL nucleus at an interstimulus interval of $100 \mathrm{msec}$ usually resulted in strong depression of all cortical field potentials and their corresponding sinks and sources (Fig. 4B). This "decremental response" was very strong at all intervals shorter than $\sim 200$ msec (Fig. 5, open circles). A similar paired-pulse depression was generated by stimulation of the medial lemniscus while recording in the same cortical location (not shown).

In some cases, paired stimulation of VPL elicited a first response typical of VPL, but a second pulse delivered $100 \mathrm{msec}$ later 

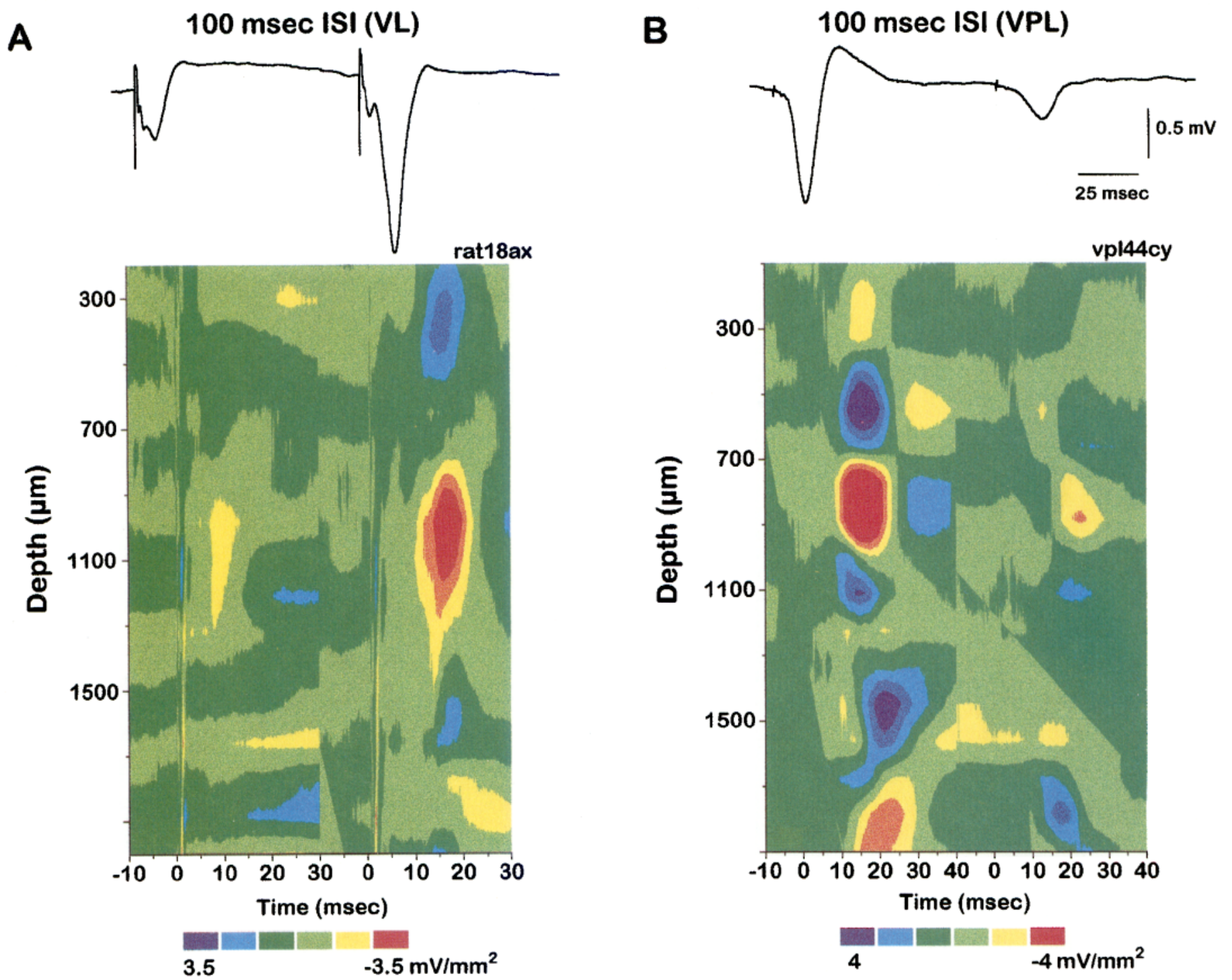

Figure 4. A, Augmenting response to paired VL stimuli. Pairs of stimuli $(150 \mu \mathrm{A})$ were delivered to the VL nucleus at an interstimulus interval of 100 $\mathrm{msec}$, while recording in the primary motor cortex (anterior-posterior $=1 \mathrm{~mm}$, lateral $=3 \mathrm{~mm}$ ). The upper trace shows an example of a trace recorded at $1000 \mu \mathrm{m}$. The bottom $C S D$ was derived from the same site. Forelimb movement was elicited at low threshold $(21 \mu \mathrm{A})$ from stimulation of the infragranular layers at this site. $B$, Decremental response to paired VPL stimuli. Pairs of stimuli $(150 \mu \mathrm{A})$ were delivered to the VPL nucleus at an interstimulus interval of $100 \mathrm{msec}$, while recording in the somatosensory cortex (anterior-posterior $=1 \mathrm{~mm}$, lateral $=4 \mathrm{~mm}$ ). The upper trace shows an example of a trace recorded at $800 \mu \mathrm{m}$. The bottom CSD was derived from the same site. Movements were not elicited when the infragranular layers were stimulated at this cortical location.

evoked a long-latency response more characteristic of VL-evoked responses. Figure $7 A$ shows an example. Such responses showed much less depression than the decremental response cases (Fig. $4 B$ ); however, the response to the second pulse was delayed significantly with respect to the first response (Fig. 7A). This effect was observed when the VPL-stimulating electrode was placed adjacent to the VL, as observed with histological analysis, or when large stimulation currents were used. Figure $7 B$ illustrates an example of the different stimulus intensities necessary to generate an augmenting response when stimulating with independent electrodes in VL and in VPL. Low intensity stimuli, which produced a robust augmenting response when applied to VL, generated only a decremental response from VPL; only the highest currents elicited an augmenting response from VPL.

The topography of VPL-to-cortex responses is shown in
Figure 8, which plots the peak negative amplitude of the field potentials at the cortical surface and at four subpial depths. The response to the first VPL stimulus was relatively large (Fig. 8) compared with that of the primary VL responses (Fig. 6). At interstimulus intervals of $100 \mathrm{msec}$, the area of the second VPL response was reduced in extent compared with the first response (Fig. 8). If the area occupied by the spread of activity from VL (Fig. 6A) is compared with the area of the primary response to VPL (Fig. 8), it is clear that there is a large region of overlap. This overlap helps to explain the result in Figure $7 A$, where paired VPL stimulation $(300 \mu \mathrm{A})$ produced a primary response and a delayed augmenting response in the somatosensory cortex (anterior-posterior $=1 \mathrm{~mm}$, lateral $=4$ $\mathrm{mm}$ ). The augmenting response was likely triggered by the spread of current from the stimulating electrode to the adja- 


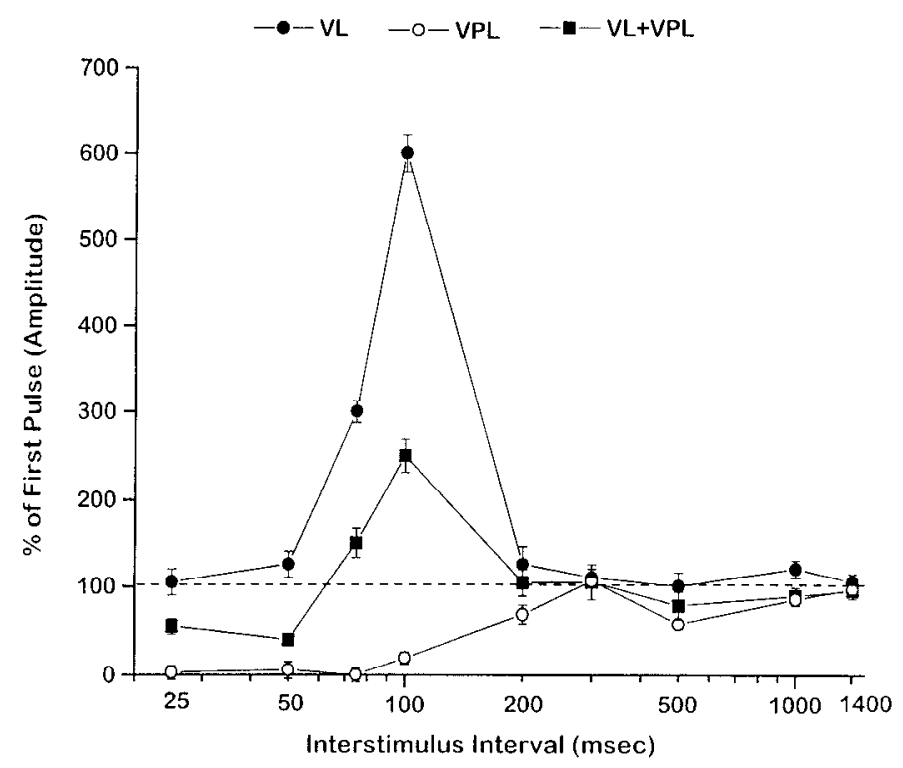

Figure 5. Effects of paired-pulse thalamic stimulation as a function of interstimulus interval. Data are expressed as the percentage of change in the amplitude of the second response, as compared to the first response, measured at a subpial depth of $800 \mu \mathrm{m}$. Interstimulus interval is represented by a semilogarithmic scale. Graph plots results from stimulation of $V L(\odot)$ or $V P L(O)$ or simultaneous stimulation of both nuclei $(V L+V P L)$ $(\square)$. Data points are the mean \pm SEM from three representative animals in which stimulating electrodes were located in VL and in VPL, allowing the independent or conjoint stimulation of the nuclei.

cent VL nucleus, activating the augmenting responsegenerating mechanism in the primary motor cortex, which spread to the recording site in somatosensory cortex.

\section{Temporal and spatial characteristics of interacting VL and VPL responses}

We stimulated the VL and VPL nuclei with separate electrodes to gauge the interactions between these parallel afferent systems. In each case we first determined the effect of paired stimulation of the VPL nucleus alone, then of the VL nucleus alone, and subsequently of both simultaneously. Figure $9 A, B$ shows the typical paired-pulse VPI decremental response and VI augmenting response at intervals of $100 \mathrm{msec}$. When paired stimuli were applied to VL and VPL simultaneously, the second response was larger compared with the second responses of either VL or VPL alone (Fig. 9C,D); the augmenting response was also delayed compared with the primary response at this cortical location (anterior-posterior $=1 \mathrm{~mm}$, lateral $4 \mathrm{~mm}$ ). This implies further that when a delayed and augmented response is observed from stimulation of the VPL nucleus alone (Fig. 7A), it is attributable to intrathalamic current spread to the adjacent $\mathrm{VL}$ nucleus or its projections. Figure 5 (filled squares) plots the relative size of the second response to simultaneous VL and VPL stimulation as a function of interstimulus interval, and it shows a relationship intermediate between those derived from VL or VPL stimulation alonc. The cortical topography of simultancous VL and VPL activation was assessed by placing a stimulating electrode at the boundary between VL and VPL. This experiment revealed a large territory of activation to the first pulse, typical of VPL stimulation, and a large lateral expansion of the affected cortical territory to the second pulse, typical of VL stimulation (not shown). Therefore, the spatiotemporal characteristics of VPL and VL stimulation can be elicited conjointly, indicating that they may interact to produce different patterns of thalamocortical activation.
We investigated the extent to which responses observed under anesthetized conditions are also observed in awake animals. Figure 10 shows characteristic examples recorded in freely moving animals during awake immobility while the VL or VPL nucleus was stimulated. Stimulation under unanesthetized conditions revealed the same response patterns as those described during anesthesia: augmenting responses from $\mathrm{VL}$ and decremental responses from VPL.

\section{Origins of the evoked responses}

To assess the possible role of intrathalamic mechanisms and/or antidromic activation of corticothalamic cells in the present results, we performed several control experiments. First, we confirmed that augmenting and decremental cortical responses do not require intrathalamic processes. Inactivating the thalamus with large infusions of $\gamma$-aminobutyric acid (GABA; $20-50$ $\mathrm{mm}$ ) or kynurenic acid did not significantly affect either VL- or VPL-evoked cortical responses. As a control, much smaller infusions of these drugs into the cortex reversibly blocked all evoked synaptic activity. Sccond, we obtained evidence that antidromically activated corticothalamic axons do not contribute to our VL- or VPL-evoked responses. When glutamate antagonists (200 $\mu \mathrm{M}$ 6-cyano-7-nitroquinoxaline-2,3-dione and $50 \mu \mathrm{M}$ AP5) were infused locally to block all synaptic activity in the cortical recording area, stimulation of VL or VPL evoked either no response or in some cases a small and localized field potential with a peak latency of $\sim 1 \mathrm{msec}$. This nonsynaptic field potential is unlikely to reflect the antidromic firing of layer VI corticothalamic cells, because these have generally slow and variable conduction velocities incompatible with a $1 \mathrm{msec}$ latency (Ferster and Lindstrom, 1983; Swadlow, 1994) and higher thrcsholds as compared with orthodromic activation of thalamocortical afferents (Ferster and Lindstrom, 1983). It is also notable that the typical current used in our study (i.e., 100 $\mu \mathrm{A}$ ) is one order of magnitude smaller than the currents used in previous studies to elicit the antidromic activation of corticothalamic cells (Ferster and Lindstom, 1985a,b).

\section{DISCUSSION}

We have studied two thalamocortical pathways of the frontoparietal (i.e., motor and somatosensory) neocortex of the rat and have characterized two types of responses that differ sharply in temporal and spatial pattern and anatomical origin. To summarize the results, single stimuli to $V L$ produced a small current sink in layer $\mathrm{V}$, whereas stimulation of VPL elicited a large current sink that began in layer IV and spread strongly to the upper layers. Paired stimuli to VL produced strong enhancement, the augmenting response, with peak effectiveness at intervals of $\sim 100 \mathrm{msec}$. In contrast, paired stimuli of VPL yielded nearly total depression, the decremental response, at intervals $<200 \mathrm{msec}$. These responses could not be attributed to the antidromic activation of corticothalamic cells, intrathalamic mechanisms, or anesthesia. Recordings from multiple sites revealed that single VL stimuli activate a very limited region of cortex, but a second VL stimulus arriving within 50-200 msec synchronized the activity across an area several times larger. In contrast, the cortical area activated by a single stimulus delivered to VPL was large, and it strongly overlapped the area of primary VL input. An additional stimulus to VPL, arriving within $200 \mathrm{msec}$, activated a much smaller region. 
A

RAT3N (VL)

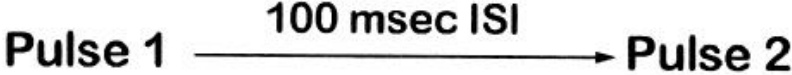

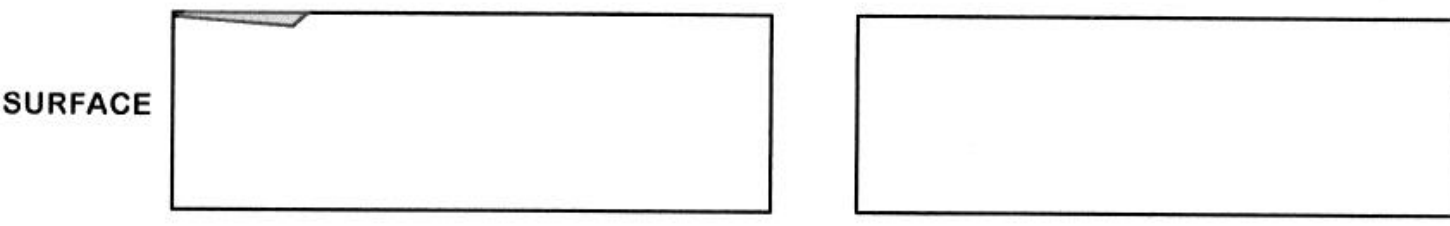

500
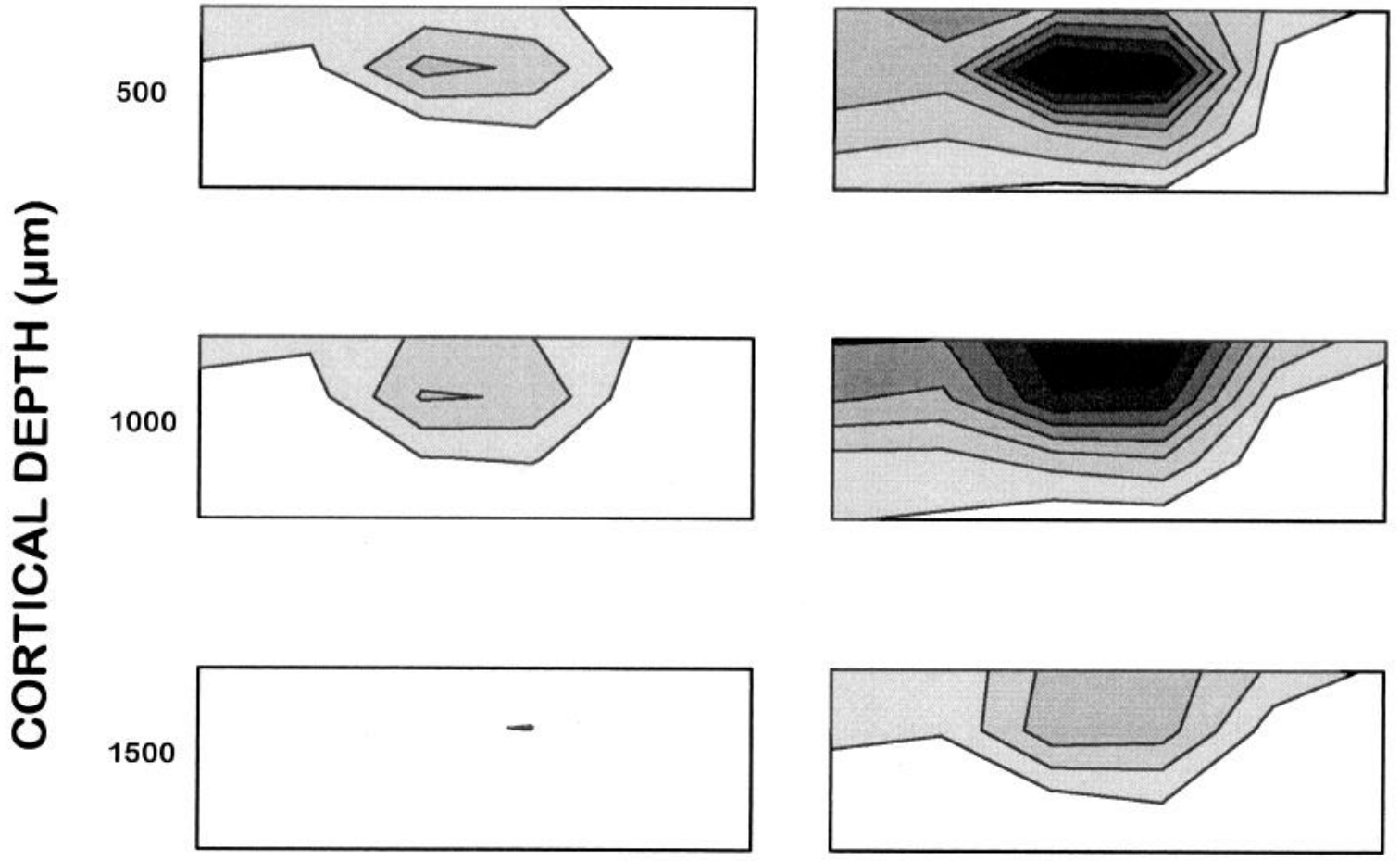

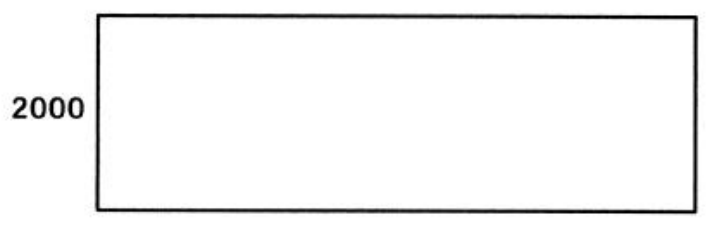

ANTERIOR-POSTERIOR $(\mathrm{mm})$

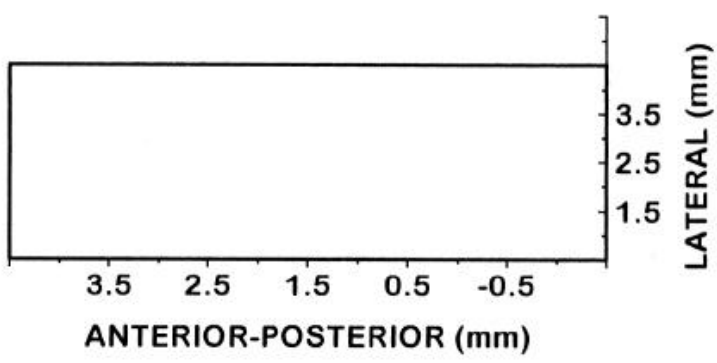

ANTERIOR-POSTERIOR $(\mathrm{mm})$

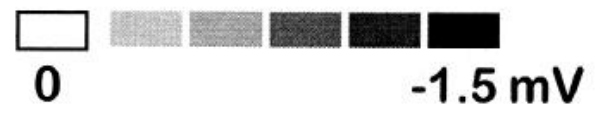

Figure 6. Topography and timing of the augmenting response induced by paired VL stimuli. $A$, The augmenting response activates a larger area of cortex than the primary response. Each panel illustrates response magnitude evoked at a grid of 24 equally spaced $(1 \mathrm{~mm})$ electrode sites (see Fig. $1 A$ ), recorded at the subpial depth listed to the left. Panels on the left show the effect of the first stimulus, panels on the right show the effect of the second stimulus delivered; the interstimulus interval was $100 \mathrm{msec}$. The gray scale represents the maximum negativity of the local field potential. Each panel represents the cortical surface from 0.5 to $4.5 \mathrm{~mm}$ lateral and from 4.5 to $-1.5 \mathrm{~mm}$ anterior-posterior from bregma. $B$, Development of the augmenting response. The same data from $A$ are shown at intervals of 3,5,7,9, or $12 \mathrm{msec}$ after the first (left) or second (right) stimulus. Only responses measured at a subpial depth of $1500 \mu \mathrm{m}$ are illustrated. Figure continues. 
B

RAT3N (VL) $1500 \mu m$

\section{$100 \mathrm{msec}$ ISI}

3
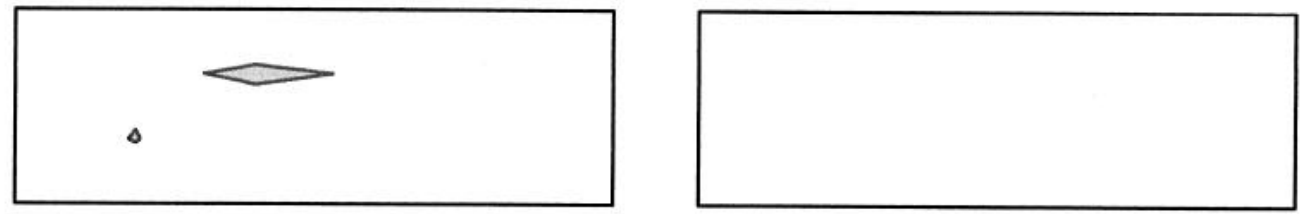

5
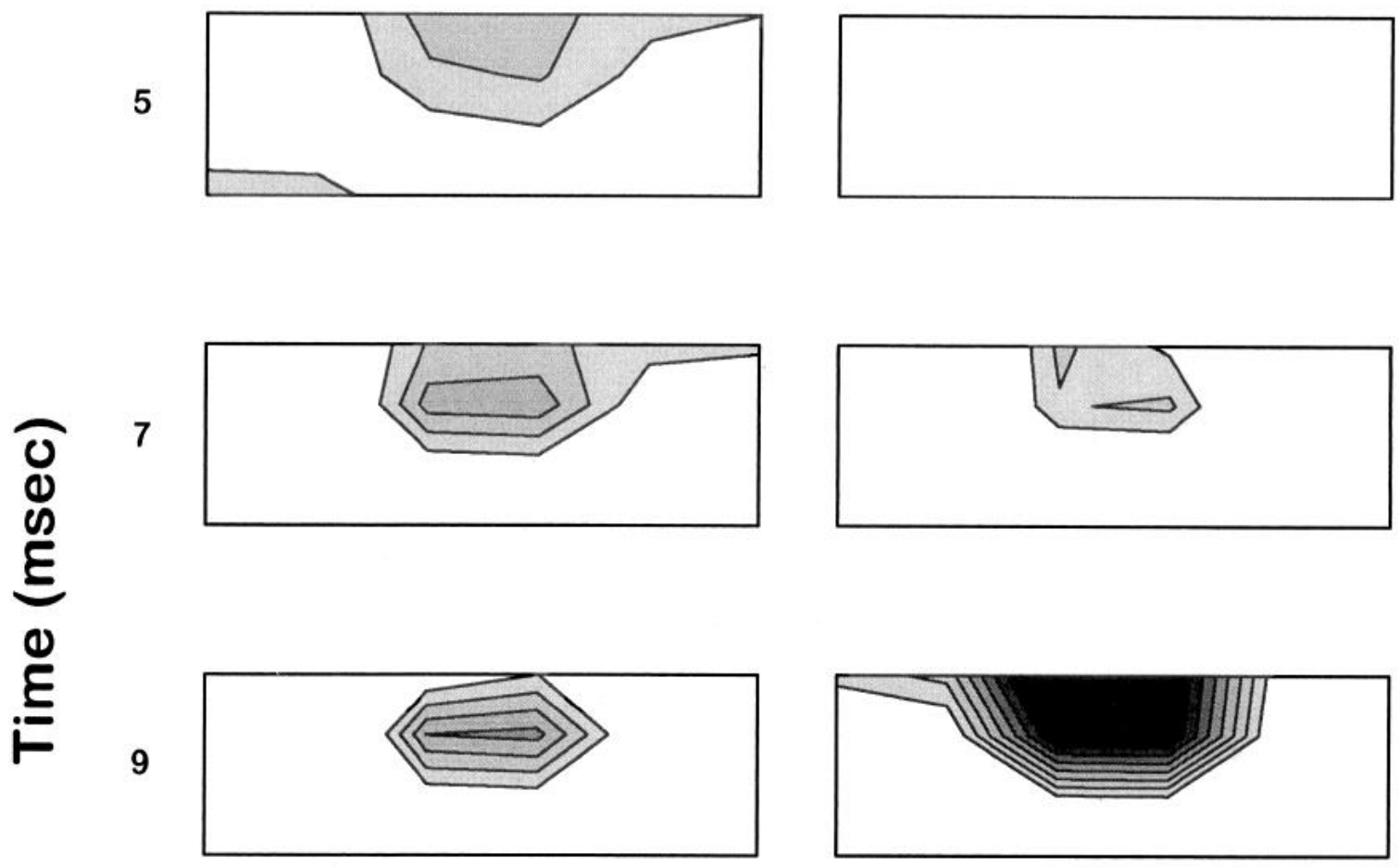

12

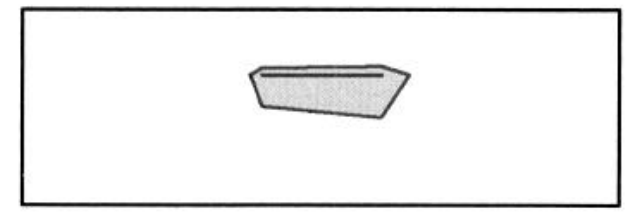

ANTERIOR-POSTERIOR (mm)

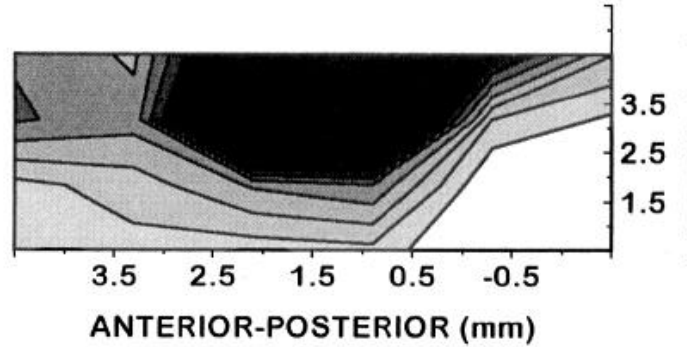

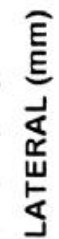

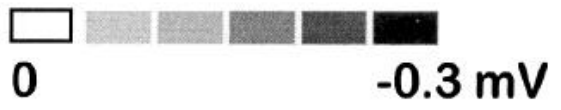

Figure 6 continued.

\section{Spatiotemporal characteristics of} thalamocortical responses

CSD analysis indicated that the VL and VPL nuclei activated different cortical laminae. VL stimulation induced a small current sink in layer $\mathrm{V}$ and a simultaneous current source in the upper layers. This pattern suggests that the synapses of VL afferents terminate on the basal dendrites of layer $\mathrm{V}$ pyramidal neurons, creating local current sinks and distal current sources in their vertically oriented apical dendrites (Cauller and Connors, 1994). In clear contrast, the relatively large current sink 
A
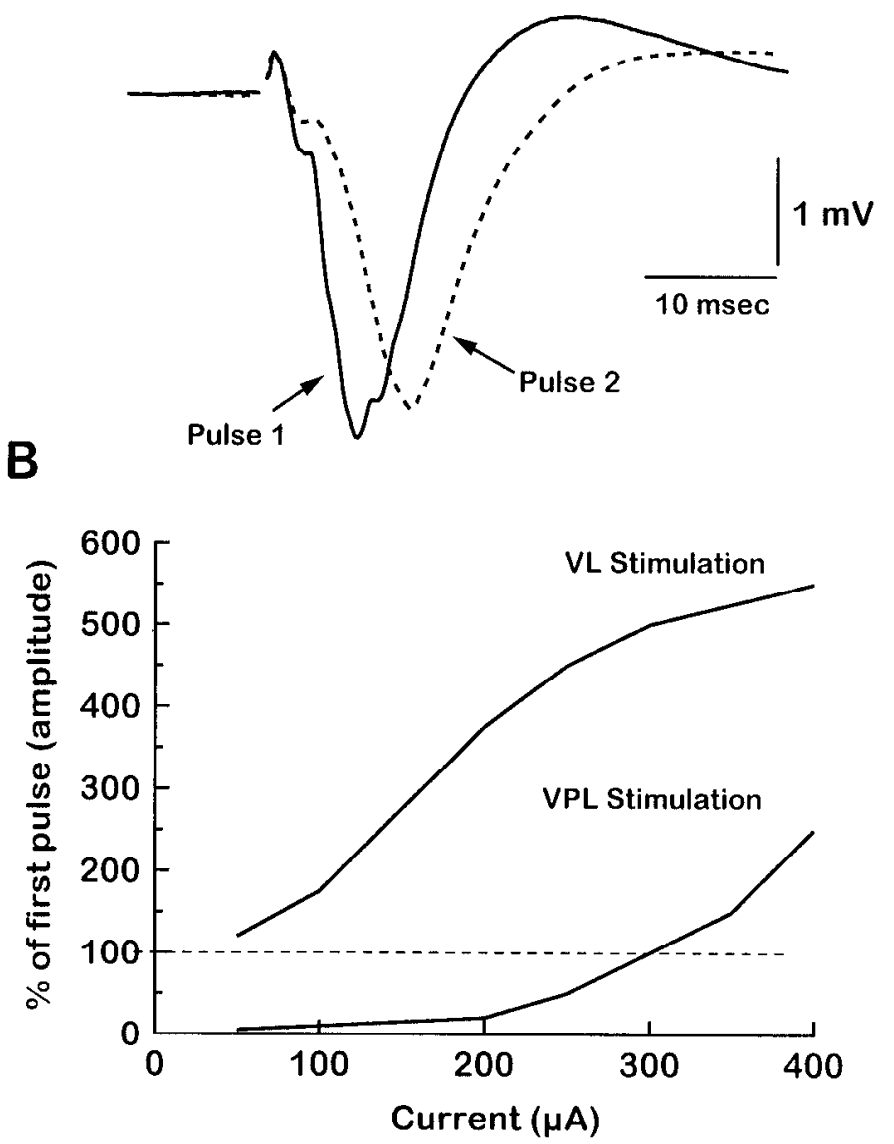

Figure 7. A, Decremental and delayed augmenting response to paired VPL stimulation. $A$, Field potentials in response to strong paired stimuli $(300 \mu \mathrm{A})$ applied to VPL and recorded at a subpial depth of $800 \mu \mathrm{m}$ in the somatosensory cortex (anterior-posterior $=1 \mathrm{~mm}$, lateral $=4 \mathrm{~mm}$ ). Traces to the first (solid line) and second (dashed line) stimulus to VPL at a $100 \mathrm{msec}$ interstimulus interval are superimposed for comparison. Note the delay of the second response compared with the first. $B$, The augmenting response threshold from stimulation of VPL is much higher than from VL. Paired stimuli were delivered to independent stimulating electrodes placed in the VL and VPL nuclei, while recording in sensorimotor cortex (anterior-posterior $=1 \mathrm{~mm}$, lateral $=3.5 \mathrm{~mm}$ ). The graph plots the percentage change of the second response relative to the first (as in Fig. 5), as a function of stimulation intensity.

produced by VPL stimulation was more superficial than the VL sink, implying VPL terminations in layer IV and subsequent polysynaptic activation of the supragranular layers. Results similar to those observed from VPL stimulation were obtained from CSD analysis of the cat thalamocortical system in vivo (Mitzdorf and Singer, 1978) and from mouse thalamocortical slices maintained in vitro (Agmon and Connors, 1991). The patterns of short-latency current sinks correlate well with the location of VPL afferent terminations assessed with anterograde tracers (Keller et al., 1985; White, 1986; Bernardo and Woolsey, 1987; Agmon and Connors, 1991; Lu and Lin, 1993), which show dense projections to layers IV and lower III. To our knowledge, however, similar studies using anterograde tracers in the VL nucleus of the rat have not been reported. Herkenham $(1980,1986)$ used tritiated amino acids infused into the VL nucleus of the rat and observed a main projection to layers I, III, and V, in clear contrast to the VPL projection to layers IV and VI. In general, our results indicate that augmenting responses are induced when the VL thalamocortical pathway activates cortical layer $\mathrm{V}$, whereas decremental responses are revealed by a VPL pathway projecting to layers IV-III.

CSD analysis and topographic maps also showed that the primary cortical response induced by VL stimulation is much smaller than that from VPL. There are several possible reasons for this. VL afferents may be sparser than afferents from VPL. Single VL afferents may be more restricted in their cortical arborizations. $\mathrm{VL}$ input to layer $\mathrm{V}$ might be masked by a stronger feedforward inhibitory drive than that from VPL to layer IV. The synaptic strength of single VL boutons may be smaller than those from VPL. There is scant evidence to distinguish between the possibilities. The VPL-evoked response was not only larger than the VL-evoked response, it was more complex in pattern because more components can be differentiated in the traces and CSDs. This difference in complexity between VL- and VPL-evoked responses has been pointed out previously in the cat (Steriade et al., 1969) and suggests a more complex cortical activation by the VPL projection.

Anatomical studies of the rat have shown extensive overlap in the cortical projections of the VL and VPL nuclei. HRP infusions into restricted cortical regions label cells in both thalamic nuclei (Donoghue et al., 1979). Our results are consistent with this, because spatial maps of cortical activation attributable to shortlatency VL and VPL stimulation overlapped considerably. This overlap must necessarily lead to interaction between the two afferent systems. Indeed, when VPL and VL were stimulated conjointly, both response systems were activated, and the laminar, topographic, and temporal profiles in the cortex differed from those of either system activatcd alonc. Thus, the activity of large regions of sensorimotor cortex must depend on the balance of input from these two afferent systems. We conclude that thalamocortical afferents originating from different nuclei and projecting to different layers of the same neocortical area give rise to distinct spatiotemporal responses, which may serve the functional specializations of these pathways.

Paired stimuli revealed the most striking differences between VL and VPL activation of cortex. With interstimulus intervals $<200$ msec, the primary response from VPL strongly decremented; however, at similar intervals, VL induced a strong augmenting response and VPL did not. Previous reports (Morin and Steriade, 1981; Ferster and Lindstrom, 1985a) showed both a decremental response and the augmenting response during $10 \mathrm{~Hz}$. stimulation delivered to the LGN or VPL in the cat. No previous study, however, has shown these responses elicited independently (i.e., each elicited from a different thalamic nuclei) or has attributed them to pathways projecting to different neocortical layers. The difference between those studies and this one might be attributable to the species used or other aspects. A distinct pattern of activation of VPL afferents between cat and rat could easily account for this difference; VPL afferents may activate layer V in the cat, or the upper layers of cat neocortex may contain the machinery necessary for triggering an augmenting response. The findings of our study are in close agreement with a previous study in the cat (Steriade, 1970) showing that VL- and VPL-induced thalamocortical responses differ sharply in their sensitivity to activation of the reticular formation; VPL-induced primary responses were enhanced, whereas VL-induced primary and augmenting responses were reduced, suggesting that they activate different cortical systems. 


\section{Pulse $1 \stackrel{100 \mathrm{msec} \text { ISI }}{\longrightarrow}$ Pulse 2}

RAT41 (VPL)
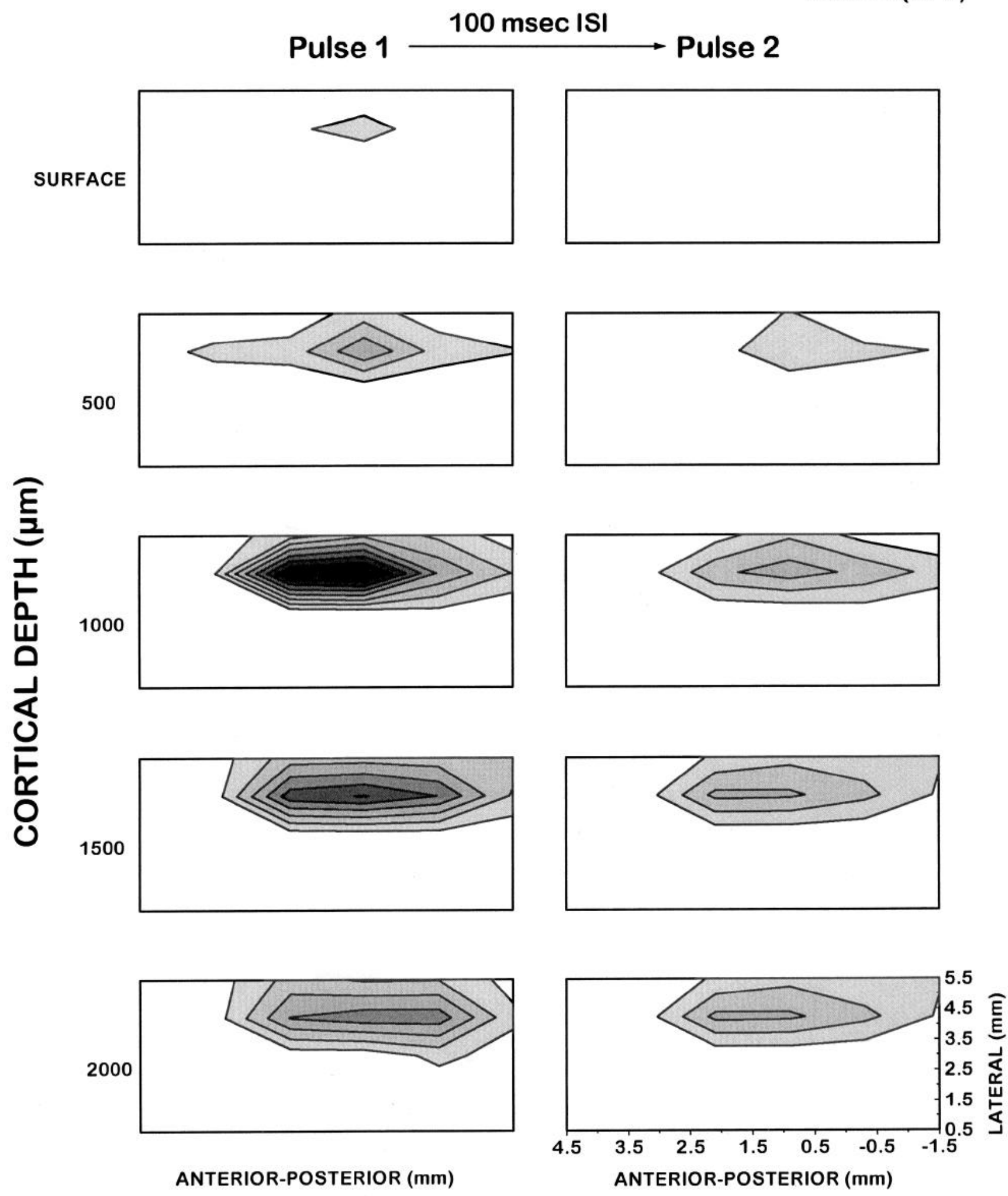

ANTERIOR-POSTERIOR (mm)
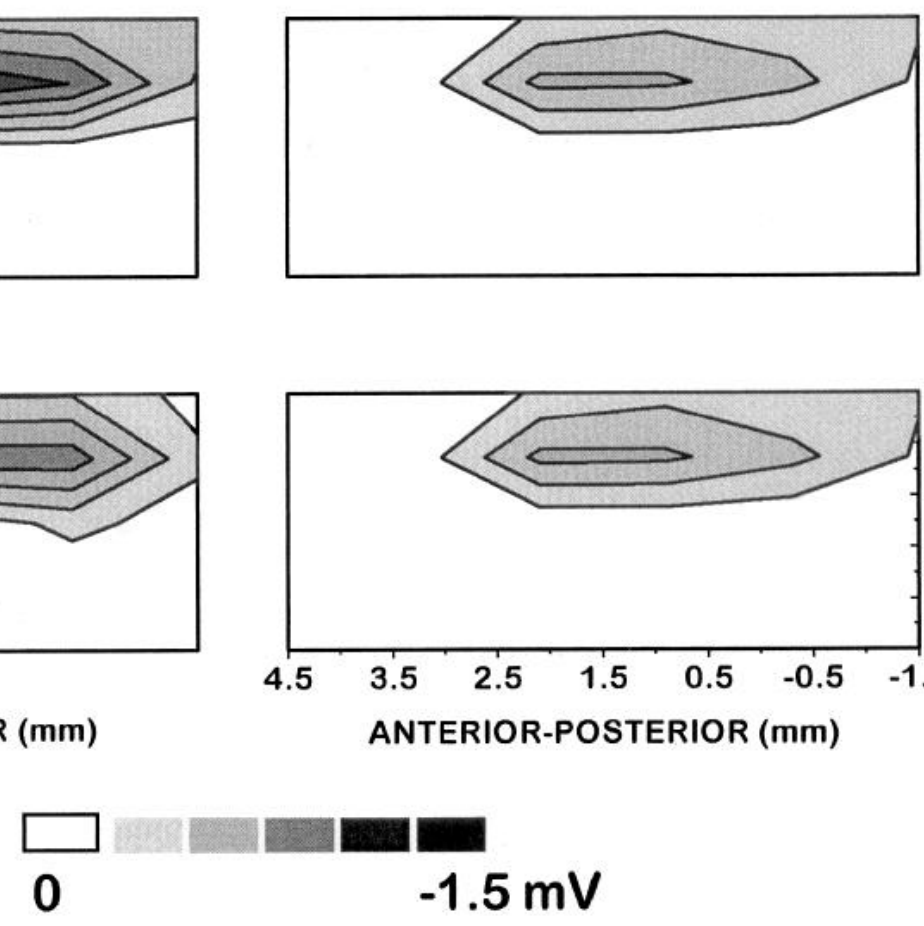

Figure 8. Topography of decremental responses induced by paired VPL stimuli. Each panel illustrates response magnitude evoked at a grid of 30 equally spaced $(1 \mathrm{~mm}$ ) electrode sites (see Fig. $1 A$ ), recorded at the subpial depth listed to the left. Panels on the left show the effect of the first stimulus, and panels on the right show the effect of the second stimulus delivered; the interstimulus interval was 100 msec. The gray scale represents the maximum negativity of the local field potential. Each panel represents the cortical surface from 0.5 to $5.5 \mathrm{~mm}$ lateral and from 4.5 to $-1.5 \mathrm{~mm}$ anterior-posterior from bregma. 
A

B

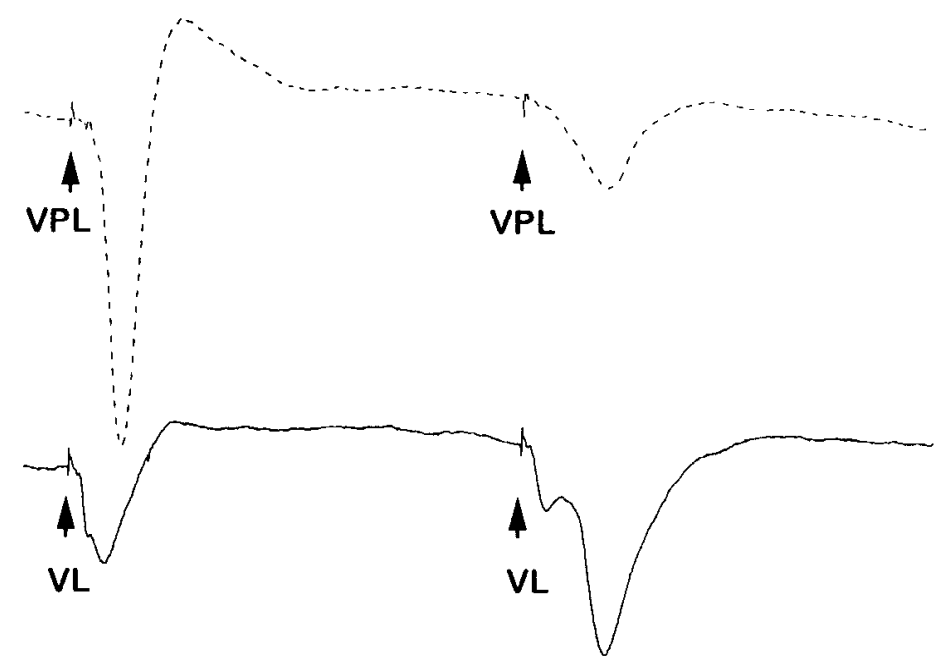

C

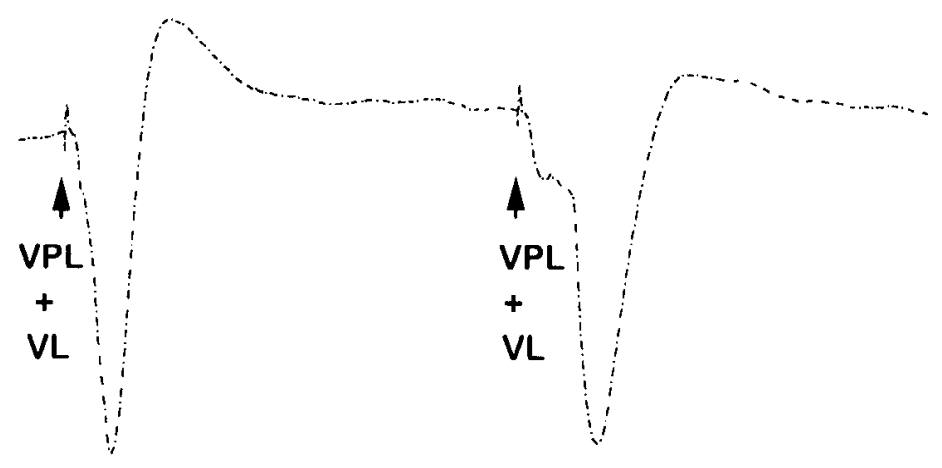

D

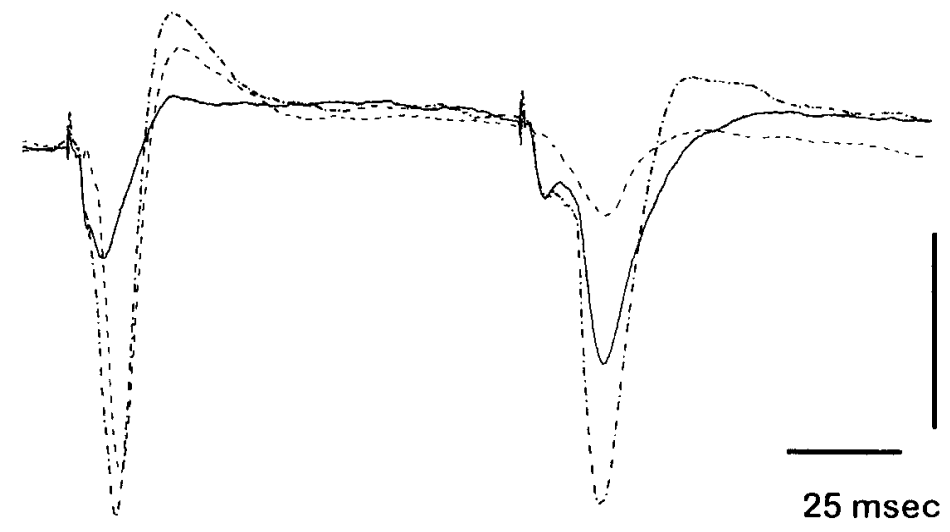

Figure 9. Interactions between VL- and VPLinduced responses in cortex. Separate stimulating electrodes were placed in VPL and VL, while recording in sensorimotor cortex (anterior-posterior $=1 \mathrm{~mm}$, lateral $=4 \mathrm{~mm}$ ) at a subpial depth of 800 $\mu \mathrm{m}$. Stimulation sites for this case are shown in Figure $1 B, C$. Interstimulus interval was 100 irsec; and intensity was $150 \mu \mathrm{A}$ in each nucleus. $A$, VPL stimulation produced a decremental response. $B$, VL stimulation produced an augmenting response that was relatively delayed at this cortical recording site. $C$, Simultaneous VL and VPL stimuli produced a large primary response and a delayed augmenting response. $D$, Superimposed traces from $A-C$.

\section{Possible mechanisms and functional implications}

The mechanisms of both augmenting and decremental responses have remained elusive, although they originate in the cortex (Morin and Steriade, 1981; Ferster and Lindstrom, 1985a) (see Results). The present study was not specifically aimed at investigating the mechanisms involved in the short-term plasticity of thalamocortical pathways; however, any mechanism proposed for the augmenting response must consider several findings of this study. (1) Consistent with previous findings (Addae and Stone, 1987), NMDA-receptor activation is not involved in generating the augmenting response because it occurs in ketamineanesthetized animals with robustness similar to that in unanesthetized animals. (2) The cells or circuits responsible for the triggering mechanism are very likely located in cortical layer $\mathrm{V}$ and should have long dendrites projecting upward. This is suggested by the layer $\mathrm{V}$ current sink and complementary upper layer current source generated during the augmenting response. (3) The cells generating the augmenting response should be able to spread activity to adjacent cortical regions via long intracortical axon collaterals. This is suggested by the very effective spread of the response over a large cortical region. (4) The mechanism requires either only a sparse input to be activated or the relatively short-latency activation of inhibition. Thus, the augmenting response or its mechanism must always be primed by a previous stimulus. These requirements implicate the pyramidal cells of layer $\mathrm{V}$ in the mechanisms underlying the augmenting response. There is a subpopulation of layer $\mathrm{V}$ cells with the intrinsic ability to discharge rhythmically at the same frequency intervals that produce an augmenting response (Silva et al., 1991). In addition, these cells have a demonstrated propensity to generate synchronous, epileptiform activity (Connors and Amitai, 1995). Intracellular recordings under the conditions described here support the 
A

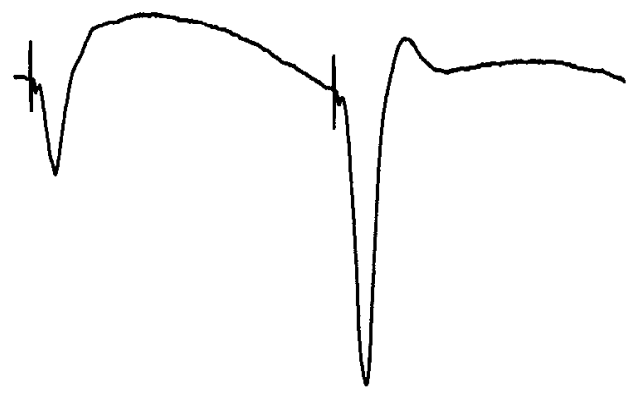

B

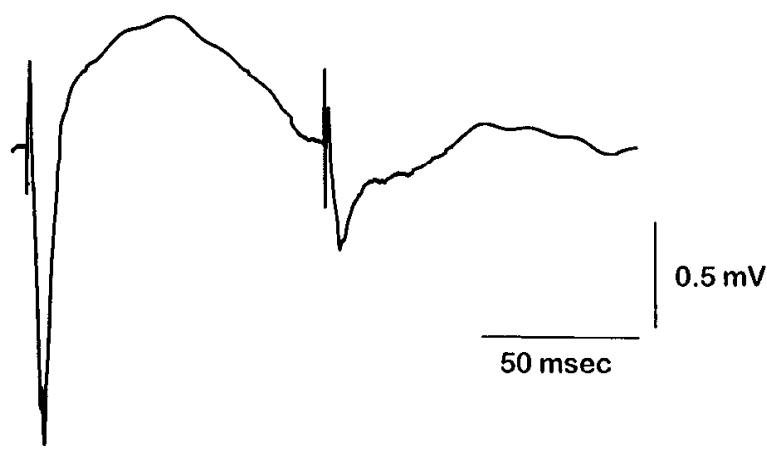

Figure 10. Augmenting and decremental responses are observed in freely moving animals. $A$, Typical response elicited in a freely moving nonanesthetized rat during awake immobility by stimulating in VL with a pair of pulses at a $100 \mathrm{msec}$ interstimulus interval. The response resembled the augmenting response recorded under anesthesia. $B$, Typical response elicited in a freely moving nonanesthetized rat during awake immobility by stimulating in VPL with a pair of pulses at a 100 misec interstinulus interval. The response resembled the decremental response recorded under anesthesia.

hypothesis that layer $\mathrm{V}$ pyramidal cells, activated monosynaplically by VL afferents and then phasically inhibited, are the critical trigger for the augmenting response (Castro-Alamancos and Connors, 1995).

Additional research will have to deal not only with the mechanisms of augmenting and decremental responses, but also with the different roles that these processes might play in cortical physiology. Interestingly, activation of cells in the somatosensory cortex by sensory input is strongly dependent on the frequency of the stimulus. Interstimulus intervals that elicited a decremental response in the present study elicit a strong depression in cortical cell discharge in response to stimulation of facial vibrissae (Simons, 1985). Recordings of neuronal discharges from multiple levels of the somatosensory system and motor cortex in freely moving rats has revealed an oscillation with frequencies similar to those that induce the augmenting response described here (Nicolelis et al., 1995). This oscillation began and spread within the cortex and then was relayed into subcortical areas. It is possible that the mechanisms responsible for the augmenting response are involved in the genesis of this behaviorally significant oscillation. Thus, decremental and augmenting responses may play a role in processes that synchronize neural activity among large cortical areas, or they amplify or filter synaptic inputs of specific frequencies. In addition, we found recently that the motor cortex (i.e., principal recipient of VL inputs) and somatosensory cortex (i.e., principal recipient of VPL inputs) of rats are strikingly different in their ability to generate some forms of long-term synaptic plasticity (Castro-Alamancos et al., 1995), which depends on the properties of short-term plasticity displayed by the activated pathways (Castro-Alamancos and Connors, 1996). Therefore, the variable frequency dependence of thalamocortical pathways may also help to determine the nature of interactions with the short- and long-term frequency-dependent processes of the cortex itself.

\section{REFERENCES}

Addae JI, Stone TW (1987) Involvement of $N$-methyl-D-aspartate reccptors in the augmenting response in rat neocortex. Neurosci Lett $78: 323-327$

Agmon A, Connors BW (1991) Thalamocortical responses of mouse somatosensory (barrel) cortex in vitro. Neuroscience 41:365-379.

Bernardo KL, Woolsey TA (1987) Axonal trajectories between mouse somatosensory thalamus and cortex. J Comp Neurol 258:542-564.

Castro-Alamancos MA, Borrell J (1993) Reversal of paw preference after ablation of the preferred forelimb primary motor cortex representation of the rat depends on the size of the forelimb representation. Neuroscience 52:637-644.

Castro-Alamancos MA, Borrell J (1995) Functional recovery of forelimb response capacity after forelimb primary motor cortex damage in the rat is due to the reorganization of adjacent areas of the cortex. Neuroscience 68:793-805.

Castro-Alamancos MA, Connors BW (1995) Mechanisms of the augmenting response in thalamocortical pathways. Soc Neurosci Abstr 21:1017.

Castro-Alamancos MA, Connors BW (1996) Short-term enhancement and long-term potentiation in neocortex. Proc Natl Acad Sci USA 93:1335-1339.

Castro-Alamancos MA, Torres-Aleman I (1993) Long-term depression of glutamate-induced gamma-aminobutyric acid release in cerehellum by insulin-like growth factor I. Proc Natl Acad Sci USA 90:7386-7390.

Castro-Alamancos MA, Donoghue JP, Connors BW (1995) Different forms of synaptic plasticity in somatosensory and motor areas of the neocortex. J Neurosci 15:5324-5333.

Cauller LJ, Connors BW (1994) Synaptic physiology of horizontal afferents to layer I in slices of rat SI neocortex. J Neurosci 14:751-762.

Connors BW, Amitai Y (1995) Functions of local circuits in neocortex: synchrony and laminae. In: The cortical neuron (Gutnick MJ, Mody I, eds), pp 123-140. Oxford: Oxford UP.

Dempsey EW, Morison RS (1942a) The production of rhythmically recurrent cortical potentials after localized thalamic stimulation. Am J Physiol 135:293-300.

Dempsey EW, Morison RS (1942b) The interaction of certain spontaneous and induced cortical potentials. Am J Physiol 135:301-308.

Dempsey EW, Morison RS (1943) The electrical activity of a thalamocortical relay system. Am J Physiol 138:283-296.

Donoghuc JP, Kcrman KL, Ebner FГ (1979) Evidence for two organizational plans in the somatic sensory motor cortex of the rat. J Comp Neurol 183:647-663.

Ferster D, Lindstrom S (1983) An intracellular analysis of geniculocortical connectivity in area 17 of the cat. J Physiol (Lond) 342:181-215.

Ferster D, Lindstrom S (1985a) Augmenting responses evoked in area 17 of the cat by intracortical axon collaterals of cortico-geniculate cells. J Physiol (Lond) 367:217-232.

Ferster D, Lindstrom S (1985b) Synaptic excitation of neurons in area 17 of the cat by intracortical axon collaterals of cortico-geniculate cells. J Physiol (Lond) 367:233-252.

Hall RD, Lindholm EP (1974) Organization of motor and somatosensory neocortex in the albino rat. Brain Res 66:23-38.

Herkenham M (1980) Laminar organization of thalamic projections to the rat neocortex. Science 207:532-535.

Herkenham M (1986) New perspectives on the organization and evolution of nonspecific thalamocortical projections. In: Cerebral cortex, Vol 5 (Jones EG, Peters A, eds), pp 403-446. New York: Plenum.

Keller A, White EL, Cipolloni PB (1985) The identification of thalamocortical axon terminals in barrels of mouse SmI cortex using immunohistochemistry of anterograde transported lectin (Phaseolus vulgarisleucoagglutinin). Brain Res 343:159-165. 
Lu S-M, Lin RC-S (1993) Thalamic afferents of the rat barrel cortex: a light and electron-microscopic study using Phaseolus vulgaris leucoagglutinin as an anterograde tracer. Somatosens Mot Res 10:1-16.

Metherate R, Ashe JH (1994) Facilitation of an NMDA receptor mediated EPSP by paired pulse stimulation in rat neocortex via depression of GABAergic IPSPs. J Physiol (Lond) 481:331-348.

Mitzdorf U (1985) Current source-density method and application in cat cerebral cortex: investigation of evoked potentials and EEG phenomena. Physiol Rev 65:37-100.

Mitzdorf U, Singer W (1978) Prominent excitatory pathways in the cat visual cortex (A17 and $\mathrm{A} 18$ ): a current source density analysis of electrically evoked potentials. Exp Brain Res 33:371-394.

Morin D, Steriade M (1981) Development from primary to augmenting responses in the somatosensory system. Brain Res 205:49-66.

Morison RS, Dempsey EW (1942) A study of thalamo-cortical relations. Am J Physiol 135:281-292.

Morison RS, Dempscy EW (1943) Mcchanism of thalamocortical augmentation and repetition. Am J Physiol 138:297-308.

Nicolelis MAL, Baccala LA, Lin RCS, Chapin JK (1995) Sensorimotor encoding by synchronous neural ensemble activity at multiple levels of the somatosensory system. Science 268:1353-1358.
Paxinos G, Watson C (1982) The rat brain in stereotaxic coordinates. New York: Academic.

Silva LR, Amitai Y, Connors BW (1991) Intrinsic oscillations of neocortex generated by layer 5 pyramidal neurons. Science 251:432-435.

Simons DJ (1985) Temporal and spatial integration in the rat SI vibrissae cortex. J Neurophysiol 54:615-635.

Steriade M (1970) Ascending control of thalamic and cortical responsiveness. Int Rev Neurobiol 12:87-144.

Steriade M, Iosif G, Apostol V (1969) Responsiveness of thalamic and cortical motor relays during arousal and various stages of sleep. J Neurophysiol 32:251-265.

Steriade M, Jones EG, Llinas RR (1990) Thalamic oscillations and signalling. New York: Wiley.

Swadlow HA (1994) Efferent neurons and suspected interneurons in motor cortex of the awake rabbit: axonal properties, sensory receptive fields, and subthreshold synaptic inputs. J Neurophysiol 71:437-453.

White EL (1986) Termination of thalamic afferents in the cerebral cortex. In: Cerebral cortex, Vol 5 (Jones EG, Peters A, eds), pp 271-290. New York: Plenum.

Zucker RS (1989) Short-term synaptic plasticity. Annu Rev Neurosci 12:13-31 